\title{
DESIGN of SPEED CONTROL of HYDRAULIC MOTOR
}

\author{
Apeksha P. Bansod, Abhijeet S. Surkar'Sakshi V. Dhande \\ Student \\ Department of Mechanical \\ K.D.K. College of Engineering, Nandanvan, \\ Nagpur-440009, Maharashtra, India
}

\begin{abstract}
This study is about Hydraulic Power Pack in hydraulic system Hydraulic drives and controls have become more important due to automation and mechanization. A large number of the advanced and incredible machineries are controlled partly or totally by hydraulics. Hydraulic system is less convoluted and has less moving parts. Today drive and control framework designing is unfathomable without hydraulics. Hydraulic Power Pack gives energy to the activities of the water driven framework, likewise moves the liquid through the framework, gives a protected greatest framework working pressing factor, and furthermore helps with keeping up the liquid temperature and tidiness. Water driven Power Pack is chosen by Pressure range, ostensible force and Size of tank different boundaries.
\end{abstract}

Keywords: - Hydraulic Power Pack, Automation, mechanization, powerful machinery, Pressure range

\section{INTRODUCTION}

A hydraulic system is a drive innovation where fluid is utilized to move the energy from for example an electric motor to an actuator, like a Hydraulic chamber. The fluid is hypothetically uncompressible and the fluid's way can be adaptable similarly as an electric cable. Hydraulic system are mainly used where a high power density is needed or load requirements chance rapidly. This is especially the case in all kinds of mobile equipment such as excavators and in industrial systems some cases, different auxiliary systems such as hatches and cranes are also powered by hydraulic system. The principle justification utilizing hydrodynamics is the powerful density and besides the straightforwardness coming from utilizing less parts to acknowledge intricate and quick machines with a serious level of wellbeing.

\section{SYSTEM LAYOUT}

In this section, the system layout and operating processes are introduced. The system layout is used to achieve better speed of hydraulic motor in both clockwise and anticlockwise directions. The components used in our project are reservoir, suction strainer, check valve, pressure relief valve, $4 / 3$

\author{
Dr. A.V. Vanalkar \\ Assistant Professor \\ Department of Mechanical \\ K.D.K. College of Engineering, Nandanvan \\ Nagpur-440009, Maharashtra, India
}

direction control valve, flow control valve (throttle valve), hydraulic motor which rotates in both clockwise and anticlockwise direction.

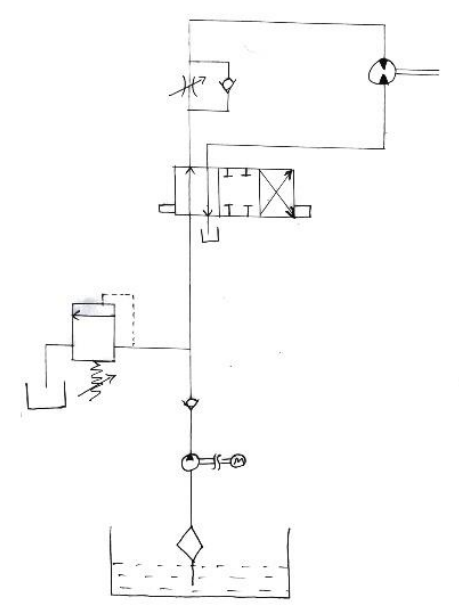

Fig 1: - The System Layout

Firstly the oil from the reservoir is supplied to the pump from the suction strainer. The pump is connected to the motor. Then the check valve is connected after the pump which allows the flow of hydraulic fluid in only one direction, the hydraulic oil cannot flow in downward direction because of check valve. After the check valve pressure relief valve is connected which is used for safety purpose we can set the system pressure with the help of pressure relief valve, when the pressure inside the system increases more than the required pressure the pressure relief valve opens and controls the pressure inside the system. Then the solenoid operated $4 / 3$ direction control valve is connected these valve has 4 ports and 3 position Forward, Backward, Neutral positions. After that the flow control valve is connected and it is connected 


\section{International Journal of Engineering Applied Sciences and Technology, 2021 \\ Vol. 5, Issue 12, ISSN No. 2455-2143, Pages 294-299 \\ Published Online April 2021 in IJEAST (http://www.ijeast.com)}

$\mathrm{S}$ hydraulic motor and the other side of hydraulic motor is connected to $4 / 3$ direction control valve and the other port of $4 / 3$ direction control valve is connected to reservoir.

\section{STUDY of COMPONENTS}

\section{Hydraulic Motor (Vane Pump)}

Fluid powered turning actuators are utilized for high force, substantial movement applications. They have high power capacities, high force per-unit weight and volume, great mechanical firmness, and high unique reaction. They give the weight to lifting, turning, indexing, clamping, mixing, bending, testing and controlling applications among others. Rotating actuators are minimized and proficient, and produce high quick torque in either direction. This makes them broadly utilized in accuracy control frameworks and hard core machine instrument, versatile, marine and aviation applications.

Specification: -

Model: - BMR-100

Displacement: - $100.5 \mathrm{~cm}^{3} / \mathrm{rev}$

Inlet Pressure: - $14 \mathrm{Mpa}$

Rotational Speed: - 10 to $600 \mathrm{rpm}$

Output Power: - $10 \mathrm{KW}$

Weight: $-7 \mathrm{Kg}$

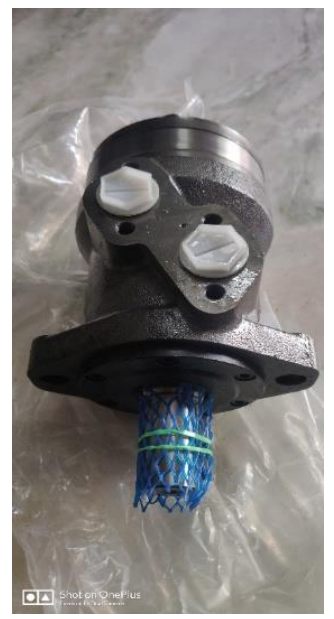

Fig 2: - Hydraulic Motor

\section{Electric Motor}

An electric Motor is an electrical machine that changes over electrical energy into mechanical energy. Most electric motors work through the connection between the engine's attractive field and electric flow in a wire twisting to create power as turn of a shaft. Electric engines can be controlled by direct flow (DC) sources, for example, from batteries, engine vehicles or rectifiers, or by substituting flow (AC) sources, like a force matrix, inverters or electrical generators.

Specification: -

Rated Voltage: - $415 \mathrm{~V}+/-10 \%$

Output Power (HP): - 3 HP $2.2 \mathrm{KW}$

Pole: - 4

Speed: - 1500 Rpm

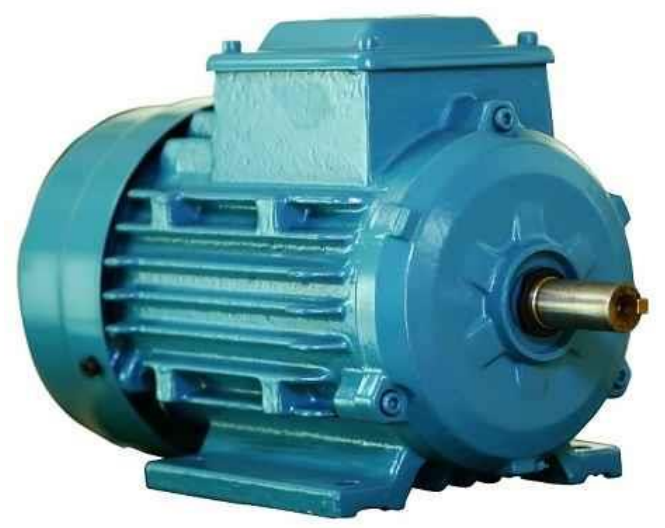

Fig 3: - Electric Motor

\section{Check Valve}

Check valves are the least complex type of pressure driven gadgets in that they permit free oil stream one way and block oil stream the other way. Check valves may likewise be utilized as a directional or pressure control in a hydraulic system. Oil is streaming in from the left side port, through the check valve and the right side port. In the event that the pressing factor levels or is higher in the right side port, the check valve will close and impede stream the other way. The check valve will impede pressure spikes back to the pump. Depending on the pressure, oil flows from the pump to the block flow or a cylinder fully strokes, the oil is rapidly deadheaded. The pressing factor in the line can rapidly increment by a few times. The check valve should then close and block the pressure spikes to the pump.

Specification: -

Model: - Polyhydron C-08

Working Pressure: - 315 bar

Temperature Range: $--20^{\circ} \mathrm{C}$ to $+80^{\circ} \mathrm{C}$

Hydraulic Medium: - Mineral Oil

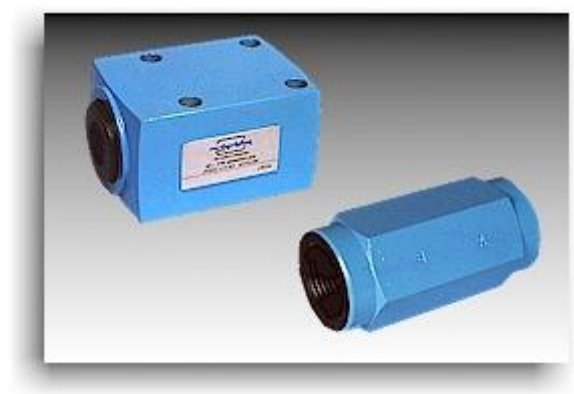

Fig 4: - Check valve 


\section{International Journal of Engineering Applied Sciences and Technology, 2021 \\ Vol. 5, Issue 12, ISSN No. 2455-2143, Pages 294-299 \\ Published Online April 2021 in IJEAST (http://www.ijeast.com)}

S

\section{Pressure Relief Valve}

A pressing factor Relief Valve is a wellbeing gadget intended to secure a compressed vessel or framework during an overpressure occasion. An overpressure occasion alludes to any condition which would make pressure in a vessel or framework increment past the predetermined design pressure or most extreme suitable working pressure. The primary part of a Pressure Relief Valve is affirmation of life and property by venting fluid from an over compacted vessel. Numerous electronic, pneumatic and hydraulic frameworks exist today to control fluid framework factors, like pressure, temperature and stream. Every one of these frameworks requires a force wellspring of some sort, for example, electricity or compressed air to work. A Pressure Relief Valve should be equipped for working consistently, particularly during a time of force disappointment when framework controls are nonfunctional. The sole wellspring of force for the Pressure Relief Valve, Therefore, is the interaction liquid.

Specification: -

Model: - DPRH06K-315

Operating Pressure: - For port P: - 400 bar

For port T: -315 bar

Pressure Setting Ranges: - Upto 25, 50, 100, 200, 315, 400 and 700 bar max

Fluid Temperature Range: $--20^{\circ} \mathrm{C}$ to $+70^{\circ} \mathrm{C}$

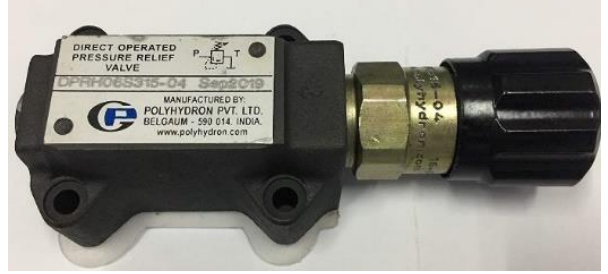

Fig 5: - Pressure Relief Valve

\section{4/3 Direction Control Valve}

Directional control valves perform just three capacities: stop liquid stream, permit liquid stream, and shift bearing of liquid stream. This direction control valve has 4 ports and 3 positions (Forward, Backward, and Neutral). A doubleacting actuator requires a 4-way valve. A 4-way valve compresses and debilitates two ports reliantly.

Specification: -

Model: - DSG01-3C60-A240-N50

Max Flow: - 45 1/min

Frequency: - $50 \mathrm{~Hz}$

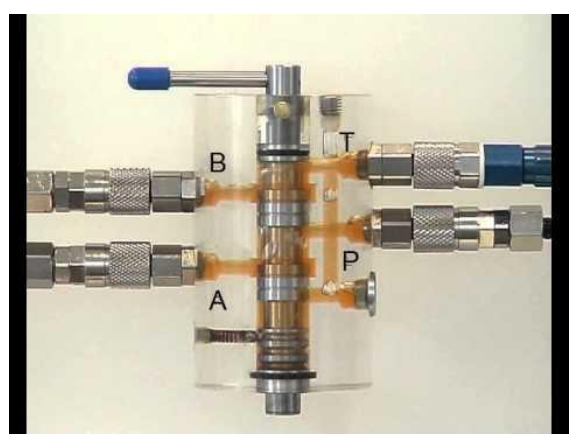

Fig 6: - 4/3 Direction Control Valve

\section{Throttle Valve}

Hydraulic throttles are utilized to change the stream pace of a pressure fluid and furthermore to manage the speed of a machine's actuating individuals. They also produce necessary pressure drops of the pressure fluid in hydraulic servomechanisms. The function of throttle valve is to restrict the flow rate of fluid or to alter the pressure of fluid in the channel. Flow control valves, which are not pressurecontrolled. The flow rate remains largely constant even at different load pressures. The stream rate control, which is free of load pressure, is accomplished through an extra control throttle.

Specification: -

Model: - DRV-16

Operating Pressure: - 350 bar

Temperature Range: $-20^{\circ} \mathrm{C}$ to $+100^{\circ} \mathrm{C}$

Max Flow: - 180 1/min

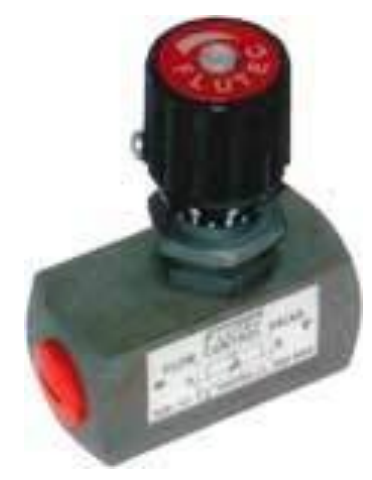

Fig 7: -Throttle Valve

\section{Suction Strainer}

A hydraulic pump "strainer" normally alludes to a mesh strainer utilized as a channel at a pump inlet. Its motivation is to sift through toxins as the hydraulic fluid methodologies the suction side of a pump. It is regularly found out if a pump suction strainer is important or suggested. The inspiration driving a suction strainer is to go probably as a particulate strainer or filter before the pump. This prevents large particles from entering the pump.

Specification: - 


\section{International Journal of Engineering Applied Sciences and Technology, 2021 \\ Vol. 5, Issue 12, ISSN No. 2455-2143, Pages 294-299 \\ Published Online April 2021 in IJEAST (http://www.ijeast.com)}

S

Model: - Fluden STR4

Media: - Wire Mesh

Capacity: - 8 LPM to 600 LPM

Size/Dimension: - 1/4" to 3"

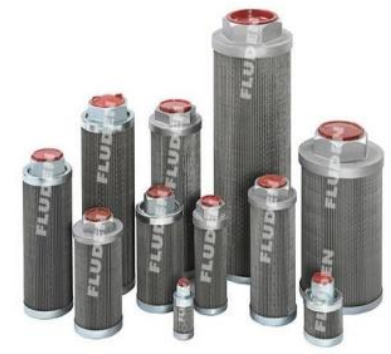

Fig 8: - Suction Strainer

\section{Hose Pipe}

Hoses are utilized to bring liquids through air or liquid conditions, and they are normally utilized with clamps, spigots, flanges, and nozzles to control liquid stream. Explicit applications incorporate the following: A nursery hose is utilized to water plants in a nursery or yard, or to pass on water to a sprinkler for a similar reason.

Specification: -

Specification of the Hose: - IS: 9573-1998 Type-4

Inner Dia of Hose: - $7.9 \mathrm{~mm}(5 / 16$ ")

Outer Dia of Hose: - $15.0 \mathrm{~mm}\left(5 / 8^{\prime \prime}\right)$

Low temperature: - $-40^{\circ} \mathrm{C} \pm 2^{\circ} \mathrm{C}$

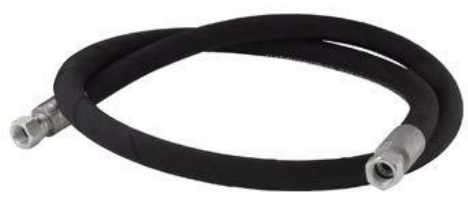

Fig 9: - Hose Pipe

\section{Reservoir}

The motivation behind the hydraulic repository is to hold a volume of liquid, move heat from the framework, permit strong toxins to settle and work with the arrival of air and dampness from the liquid. The hydraulic pump transmits mechanical energy into hydraulic energy. The hydraulic repository is a compartment for holding the liquid needed to supply the framework, including a save to cover any misfortunes from minor spillage and vanishing. The supply can be intended to give space to liquid development, permit air entrained in the liquid to get away, and to help cool the fluid.

Specification: -

A general guideline for estimating a hydraulic repository proposes that its volume should rise to multiple times the evaluated yield of the framework's fixed-dislodging siphon or mean stream pace of its variable-displacement pump. This implies a framework utilizing a 5-gpm pump ought to have a 15-gal repository.

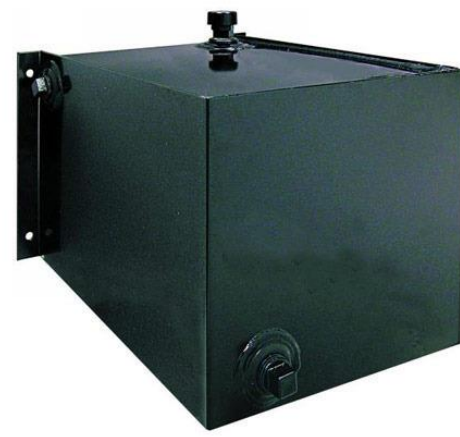

Fig 10: - Reservoir

1. Hydraulic Motor

IV. CALCULATION
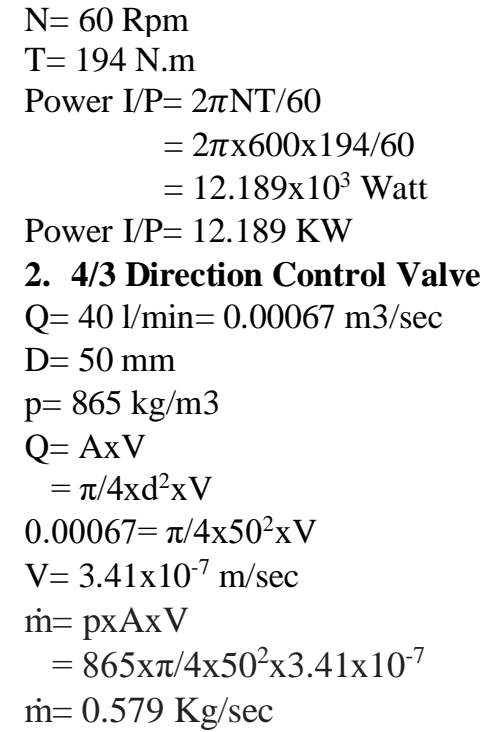

\section{Pressure Relief Valve}

Port $P\left(d_{1}\right)=6.35 \mathrm{~mm}$

Port $\mathrm{P}\left(\mathrm{d}_{2}\right)=6.6 \mathrm{~mm}$

$\mathrm{Q}=40 \mathrm{l} / \mathrm{min}=0.00067 \mathrm{~m}^{3} / \mathrm{sec}$

$\mathrm{Q} 1=\mathrm{AxV}_{1}$

$=\pi / 4 \mathrm{xd}_{1}{ }^{2} \mathrm{xV}_{1}$

$0.00067=\pi / 4 \times 6.35^{2} \mathrm{xV}_{1}$

$\mathrm{V}_{1}=2.11 \times 10^{-5} \mathrm{~m} / \mathrm{sec}$

$\mathrm{Q} 2=\mathrm{AxV} 2$

$=\pi / 4 \mathrm{xd}_{2}{ }^{2} \mathrm{xV}_{2}$

$0.00067=\pi / 4 \times 6.6^{2} \mathrm{xV}_{2}$

$\mathrm{V}_{2}=1.95 \times 10^{-5} \mathrm{~m} / \mathrm{sec}$

$\dot{\mathrm{m}}_{1}=\mathrm{pxA}_{1} \mathrm{XV}_{1}$

$=865 \times \pi / 4 \times 6.35^{2} \times 2.11 \times 10^{-5}$

$\dot{\mathrm{m}}_{1}=0.578 \mathrm{Kg} / \mathrm{sec}$

$\dot{\mathrm{m}}_{2}=\mathrm{pxA}_{2} \mathrm{xV}_{2}$ 


\section{International Journal of Engineering Applied Sciences and Technology, 2021 \\ Vol. 5, Issue 12, ISSN No. 2455-2143, Pages 294-299 \\ Published Online April 2021 in IJEAST (http://www.ijeast.com)}

$\mathrm{S}$

$=865 \times \pi / 4 \times 6.6^{2} \times 1.95 \times 10^{-5}$

$\dot{\mathrm{m}}_{2}=0.577 \mathrm{Kg} / \mathrm{sec}$

4. Check Valve

$\mathrm{d}=9.525 \mathrm{~mm}$

$\mathrm{Q}=40 \mathrm{l} / \mathrm{min}=0.00067 \mathrm{~m} 3 / \mathrm{sec}$

$\mathrm{Q}=\mathrm{AxV}$

$=\pi / 4 \mathrm{xd}^{2} \mathrm{xV}$

$0.00067=\pi / 4 \times 9.525^{2} \times \mathrm{V}$

$\mathrm{V}=9.402 \times 10^{-6} \mathrm{~m} / \mathrm{sec}$

$\dot{\mathrm{m}}=\mathrm{pxAxV}$

$=865 \times \pi / 4 \times 9.525^{2} \times 9.402 \times 10^{-6}$

$\dot{\mathrm{m}}=0.579 \mathrm{Kg} / \mathrm{sec}$

5. Throttle Valve

$\mathrm{d}=19.05 \mathrm{~mm}$

$\mathrm{Q}=\mathrm{AxV}$

$=\pi / 4 \mathrm{xd}^{2} \mathrm{xV}$

$0.00067=\pi / 4 \times 19.05^{2} \mathrm{xV}$

$\mathrm{V}=2.350 \times 10^{-6} \mathrm{~m} / \mathrm{sec}$

$\dot{\mathrm{m}}=\mathrm{pxAxV}$

$=865 \times \pi / 4 \times 19.05^{2} \times 2.350 \times 10^{-6}$

$\dot{\mathrm{m}}=0.579 \mathrm{Kg} / \mathrm{sec}$

\section{RESULT}

Thus we studied about hydraulic system and their advantages in this project. Planning new hydraulic power packs expect to improve proficiency and efficiency in all areas. Take for example, embracing remote distant controlled force packs that offer unparalleled accommodation and adaptability when dealing with a heap. In addition, utilizing smaller than normal or miniature water driven force packs that are compact offer a great deal of adaptability. This makes it conceivable to embrace these frill for practically all pressure driven applications as demonstrated in section one. In this manner, we can have them for basic or complex applications. Indeed, we hope to see significantly more water driven force pack plans in the coming years. A water powered framework is a drive innovation where a liquid is utilized to move the energy from for example an electric engine to an actuator, like a water powered chamber. The liquid is hypothetically uncompressible and the liquid way can be adaptable similarly as an electric link. Pressure driven frameworks are equipped for moving heavier loads just as giving more noteworthy power than mechanical, electrical or pneumatic frameworks. The liquid force framework implies it can undoubtedly adapt to a huge weight territory without utilizing cog wheels, pulleys or substantial leavers.

\section{CONCLUSION}

In this paper study of various parameters for selection of hydraulic power pack was done. The pump-controlled hydraulic system is a promising solution for high-efficiency construction machinery. However, the linear actuator's dynamic response and tracking accuracy are not satisfactory in its current level. In this project we studied about the various selection parameters of Hydraulic Power Pack and also the applications of hydraulic power pack was studied. Pressure driven frameworks are fit for moving heavier loads just as giving more prominent power than mechanical, electrical or pneumatic frameworks. The liquid force framework implies it can undoubtedly adapt to a huge weight territory without utilizing pinion wheels, pulleys or weighty leavers.

\section{ACKNOWLEDEMENT}

Authors have great pleasure in expressing our most sincere regards and deep sense of gratitude to our Project Supervisor/Co-supervisor

Dr.A.V.Vanalkar for his able guidance and valuable suggestion.

Authors would like to express our deep sense of gratitude to our respected Dr. Chandrahas C. Handa Professor \& Head, Department of Mechanical Engineering, K D K College of Engineering, Nagpur for his encouragement and support.

Authors feel happy to extend our heartfelt thanks to the Principal, Dr. D P Singh and Vice-Principal, Dr. A M Badar for being a source of inspiration \& motivation.

Last but not least we would like to thank entire Mechanical Engineering Department, our parents and all our friends who have helped us in completing this task successfully.

Authors

1. Apeksha P. Bansod

2. Abhijeet S. Surkar

3. Sakshi V. Dhande

4. Dr.A.V.Vanalkar

\section{REFERENCE}

[1]. A textbook of "Fluid mechanics and hydraulic machines", by Dr.R.K.Bansal 2012, LAXMI PUBLICATION.

[2]. "Design Modelling and Analysis of Standardized Hydraulic Power Pack" by Srinivas R, Mrs. Manjula, Saria Das, Bharadwaj IJRET: International Journal of Research in Engineering and Technology.

[3]. www.wikipedia.com

[4]. A textbook of "Industrial Fluid Power", by C.P.MURGUDKAR 
[5]. W. Zhou, Z. Zhao, T.S. Lee, S.H. Winoto., Investigation of flow through centrifugal pump impellers using computational fluid dynamics, International Journal of Rotating Machinery.

[6]. Habibi, S., Burton, R., Sampson, E., 2006 "High Precision Hydrostatic Actuation Systems for Microand Nanomanipulation of Heavy Loads", Transactions of the ASME, vol. 128, no. 4, pp. 778-787.

[7]. ISO4409 Hydraulic fluid power: Positive-displacement pumps, motors and integral transmissions 2007: Methods of testing and presenting basic steady state performance. Technical Report 4409, ISO.

[8]. ISO8426. Hydraulic fluid power: Positive displacement pumps and motors 2008: Determination of derived capacity. Technical Report 8426, ISO.

[9]. Shrinivas R, Mrs.Manjula, Saira Das Bharadwaj. 2015 Design modelling and analysis of standardize hydraulic power pack. In proceeding International journal of research in Engineering and Technology Vol 5.

[10]. Milos Vukovic, Sebastian Sgro, Hubertus Murrenhoff, "Steam A mobile Hydraulicsystem with engineering integration" FPMC2014-4408, October 6-9, 2014 ASME.

[11].Cristian Cardoso Locateli, Paulo Leonel Teixeira, 2014 “Digital Hydraulic system" FPNI2014-7839, June 11-13".

[12]. "Module 6 Actuators", IIT KHARAGPUR

[13]. "Various Hydraulic Pumps", IIT KHARAGPUR

[14]. "Unloading Mechanism" US Patent No 1334828. A. ldrich. Pressure Valve. US Patent No. 1757059, Rickenberg. F. 